\title{
STRATEGI PENINGKATAN PENDANAAN MANDIRI PANTI ASUHAN MELALUI PELATIHAN SABLON
}

\author{
Ani Silvia, Budi Permana, Gusti Bahari Desian Putra, Fitri Adyani Putri, Putri \\ Rahmaningrum, Nur Rahmainiwati, Citra Ayu Ratnasari, Pepi Fauziah, Regina \\ Widya Fernanda, Luthfi Febriansyah, Litra Nova Harce, Risyad Jamaran \\ Universitas Muhammadiyah Prof. DR. HAMKA \\ Email: ani.silvia.finance@gmail.com
}

Diterima: 5 Januari 2018, Direvisi: 15 Januari 2018, Disetujui: 30 Januari 2018

\begin{abstract}
ABSTRAK
Tujuan dari kegiatan Pengabdian kepada Masyarakat (PKM) ini adalah untuk mengatasi permasalahan terkait kebutuhan pendanaan operasional sebuah panti asuhan dengan menciptakan industri kreatif kecil melalui pembuatan seni grafis sablon. Permasalahan tersebut muncul karena sumber pendanaan panti asuhan dinilai sangat tergantung dari berbagai sumber bantuan sosial yang memiliki sifat tidak tetap sehingga rawan terhadap kesulitan keuangan jika budget pengeluaran lebih besar daripada sumber bantuan dana yang masuk. Solusi untuk menyelesaikan permasalahan tersebut adalah dengan meningkatkan kemandirian secara ekonomi dengan memberdayakan remaja panti melalui pemberikan keterampilan pembuatan sablon secara manual. Melalui pelatihan dan pendampingan dalam pembuatan sablon ini diharapkan tercipta kemandirian ekonomi bagi warga panti, peningkatan kreativitas dan bekal kewirausahaan bagi remaja panti.
\end{abstract}

Kata kunci: kemandirian ekonomi, pelatihan sablon manual, panti asuhan

\section{ABSTRACT}

The purpose of this community service activity is to overcome the problem related to the operational funding needs of an orphanage by creating a small creative industry through the making of screen printing graphic art. The problem arises because the funding source of an orphanage is highly dependent on various sources of social grants that are not fixed so that it is prone to face financial difficulties if the budget expenditure is greater than the source of incoming funds. The solution to solve this problem is to increase economic independence by empowering the youth of the orphanage through the provision of screen printing skills manually. Through training and assistance in making screen printing is expected to create economic independence for the orphanage, increase the creativity and can be provision of entrepreneurship for the youth of the orphanage.

Keywords: economic independence, manual screen printing, orphanage 


\section{PENDAHULUAN}

Panti asuhan atau panti sosial asuhan anak merupakan salah satu organisasi sosial, bukan organisasi bisnis, dimana organisasi tersebut tidak mengharapkan keutungan dalam bentuk materi. Anak-anak yatim, yatim piatu, anak-anak terlantar dan orang yang tidak mampu dari segi ekonomi bernaung di lembaga sosial ini. Selain mempunyai tanggung jawab untuk memberikan pelayanan kesejahteraan sosial pada anak terlantar, panti sosial asuhan juga diharapkan dapat memberikan pelayanan pengganti orang tua/wali anak dalam memenuhi kebutuhan fisik, mental dan sosial kepada anak asuh (Depsos RI, 2004). Dengan demikian mereka dapat memperoleh kesempatan yang luas bagi pengembangan kepribadian, sebagai bagian dari generasi penerus cita-cita bangsa dan sebagai insan yang akan turut serta akif dalam bidang pembangunan nasional.

Di lain sisi, dalam memberikan pelayanan dan fasilitas yang memadai bagi anak asuh, panti asuhan membutuhkan sejumlah pendanaan yang tak sedikit. Sumber pendanaan operasional panti asuhan biasanya diperoleh dari bantuan pemerintah dan berbagai sumber donatur sosial. Bantuan pemerintah, khususnya di DKI Jakarta, diatur dalam peraturan DKI Jakarta No. 174 tahun 2015 tentang bantuan biaya operasional pendidikan pasal 8 ayat 1 . Dalam peraturan ini, peserta didik yang sedang menjalani proses pendidikan dan tinggal di panti asuhan dapat diusulkan menjadi calon penerima bantuan biaya personal pendidikan dengan ketentuan memiliki Nomor Induk Kependudukan (NIK) dan terdaftar sebagai penghuni panti. Biaya personal pendidikan diberikan dalam bentuk Kartu Jakarta Pintar (KJP) dan hanya boleh digunakan untuk membeli peralatan sekolah dan sumbangan penyelengaraan pendidikan. Dapat disimpulkan bahwa bantuan dari pemerintah hanya terbatas pada bantuan terkait kebutuhan pendidikan anak asuh. Kebutuhan operasional panti asuhan seperti kebutuhan akan makanan, pakaian, listrik dan lain-lain dipenuhi dengan menggunakan dana dari bantuan donatur sosial seperti sumbangan masyarakat yang tidak mengikat, dana Zakat, Infaq dan Shodaqah (ZIS) kaum muslimin. Namun demikian bantuan dana dalam bentuk ini merupakan bantuan yang bersifat tidak tetap, sehingga panti akan sangat rawan menghadapi kesulitan keuangan apabila pengeluaran operasional lebih 
besar dibandingkan dengan dana yang masuk. Dengan demikian kebutuhan yang terjadi setiap bulannya tidak bisa terpenuhi dengan seimbang.

Dengan permasalahan yang sudah dipaparkan di atas, panti asuhan perlu untuk mencari sumber pendanaan yang lain selain dari dua sumber yang telah disebutkan sebelumnya. Sumber dana lain yang bisa dijadikan alternatif adalah dari usaha-usaha yang dilakukan pihak internal yayasan. Bidang usaha yang paling memungkinkan yang dapat dilakukan yayasan adalah usaha yang tidak membutuhkan modal yang besar (capital intensive) melainkan lebih membutuhkan jumlah tenaga kerja manusia yang cukup (labour intensive) dan kreativitas seperti di bidang ekonomi kreatif.

Simatupang (2008) mendefinisikan ekonomi kreatif sebagai sistem kegiatan manusia yang berkaitan dengan kreasi mulai dari proses produksi hingga konsumsi barang dan jasa yang bernilai kultural, artistik, estetika, intelektual dan emosional bagi para konsumen akhir. Melalui ekonomi kreatif, barang dan jasa yang diproduksi dikonversi menjadi produk yang memiliki nilai tambah yang tinggi. Berdasarkan data Bekraf (2017), sektor industri ini memberikan kontribusi cukup besar yaitu sekitar 7,38 persen terhadap total perekonomian nasional. Howkins dalam The Creative Economy (2001) mengusulkan 15 kategori industri yang termasuk dalam ekonomi kreatif, diantaranya adalah periklanan, arsitektur, seni rupa, kerajinan atau kriya, desain, desain fashion, film, musik, seni pertunjukan, penerbitan, riset dan pengembangan, piranti lunak, mainan dan permainan, TV dan radio, dan permainan video. Sedangkan di Indonesia, sektor ekonomi kreatif terbagi menjadi 16 subsektor, diantaranya adalah kuliner, fashion, kriya, televisi dan radio, penerbitan, arsitektur, aplikasi dan game developer, periklanan, musik, fotografi, seni pertunjukan, desain produk, seni rupa, desain interior, film dan desain komunikasi visual. Salah satu subsektor yang memberikan kontribusi dominan bagi perekonomian nasional adalah subsektor fashion yang menyumbangkan sekitar 18.15 persen dari total ekonomi kreatif (Bekraf, 2017).

Berbicara mengenai fashion saat ini tidak hanya sekedar esensi dalam berpakaian melainkan lebih kepada gaya hidup. Perkembangan dunia fashion yang semakin pesat menyebabkan kebutuhan akan ketersediaan fashion semakin meningkat dan terlihat dengan begitu maraknya pusat perbelanjaan yang menjual berbagai jenis gaya fashion. Karakteristik kepribadian seseorang akan terlihat dari minat fashion 
seseorang terhadap pakaian (O'Cass, 2000; O'Cass, 2004). Karya seni dapat dituangkan dalam bentuk tulisan atau desain gambar yang artistik dan estetik ke dalam sebuah pakaian. Hal ini dapat dilakukan dengan menggunakan teknik yang disebut penyablonan atau sablon.

Usaha seni grafis sablon bisa dijadikan alternatif usaha yang menghasilkan sumber dana alternatif bagi panti asuhan. Para penghuni panti yang masih berada di usia yang produktif seperti para remaja panti dapat diberdayakan untuk menyokong usaha ini. Secara prospek, usaha sablon bisa memberikan hasil yang menjanjikan karena minat fashion berpakaian masyarakat saat ini mulai beragam serta modal yang diperlukan saat memulai bisnis ini juga tidak terlalu besar.

Berdasarkan hal tersebut di atas, pengabdian ini bertujuan untuk meningkatkan pengetahuan dan keterampilan bagi warga panti khususnya para remaja panti di panti asuhan Siti Khadijah Al-Kubra mengenai teknik sablon dan praktik sablon secara manual. Diharapkan melalui kegiatan pengabdian ini dapat meningkatkan keterampilan dan kreativitas remaja panti untuk bisa memulai usaha seni grafis sablon sehingga dapat meningkatkan kemandirian ekonomi bagi panti asuhan dalam memenuhi kebutuhan operasionalnya secara seimbang.

\section{METODE}

Kegiatan pengabdian ini dilaksanakan di panti asuhan Siti Khadijah Al-Kubra yang berlokasi di Lenteng Agung, Jakarta Selatan, DKI Jakarta dengan menjadikan remaja panti menjadi subjek kegiatan. Dalam kegiatan ini dilakukan 3 tahapan pelaksanaan diantaranya adalah tahap pra-pelaksanaan, tahap pelaksanaan dan tahap pasca-pelaksanaan.

\section{Tahap Pra-Pelaksanaan}

Tahap ini dimulai dengan melakukan observasi di tempat kegiatan, pemetaan masalah dengan melakukan wawancara kepada pihak panti asuhan, dan selanjutnya berkoordinasi untuk melakukan kegiatan pelatihan teknik sablon manual dan persiapan tempat kegiatan. Sebelum melakukan kegiatan pelatihan, maka ada beberapa alat dan bahan yang harus disiapkan, diantaranya: 
Tabel 1. Alat dan Bahan

\begin{tabular}{|l|l|l|l|}
\hline No. & \multicolumn{1}{|c|}{ Alat } & No. & \multicolumn{1}{c|}{ Bahan } \\
\hline 1 & Screen & 1 & Kaos \\
\hline 2 & Rakel & 2 & Kertas HVS A4 \\
\hline 3 & Kuas & 3 & M3 \\
\hline 4 & Heat gun & 4 & Sari warna \\
\hline 5 & Printer & 5 & Bahan emulsi/Obat afdruk \\
\hline 6 & Paint remover & 6 & Pencuci screen \\
\hline 7 & Tripleks & 7 & Tinta \\
\hline 8 & Meja afdruk & 8 & Katalis \\
\hline 9 & Meja cetak & & \\
\hline
\end{tabular}

\section{Tahap Pelaksanaan Kegiatan}

Tahap pelaksanaan kegiatan dimulai dengan pemberian materi mengenai tata cara menggunakan alat sablon manual. Selanjutnya subjek kegiatan dibimbing untuk melakukan praktek secara langsung agar mampu menggunakan alat sablon manual dan meminimalkan terjadinya kekeliruan dalam menggunakan perangkat alat dan bahan sablon.

\section{Tahap Pasca-Pelaksanaan}

Dalam tahap ini, dilakukan evaluasi terhadap kegiatan yang telah dilaksanakan. Evaluasi dilakukan dengan melihat mutu produk yang dihasilkan. Untuk menjamin keberlanjutan program, tim PKM Fakultas Ekonomi dan Bisnis UHAMKA memberikan 2 perangkat alat sablon manual yaitu perangkat alat sablon untuk media kaos dan perangkat alat sablon manual untuk media kertas. Dalam tahap ini, diberikan pembekalan untuk bisa memasarkan produk baik secara offline maupun online. Kemudian subjek diberikan pengetahuan untuk mampu melakukan pencatatan laporan keuangan sederhana sehingga dapat menghitung laba dan rugi secara mandiri.

\section{HASIL DAN PEMBAHASAN}

Panti asuhan Siti Khadijah Al-Kubra menempati wilayah dengan luas 2000 meter yang merupakan wakaf dari warga Muhammadiyah di Lenteng Agung, Jakarta Selatan. Pada awal berdiri, panti asuhan ini hanya menyantuni 20 anak asuh dan kini jumlah anak asuh bertambah menjadi 23 anak yang diantaranya berasal dari daerah lain. 
Pihak panti tidak hanya sekedar memberikan bantuan saja kepada anak asuhnya, melainkan juga melakukan pembinaan secara kontinu. Selain disekolahkan mulai dari tingkat SD hingga SMU dengan dibiayai penuh dari pihak yayasan panti, anak asuh juga diberikan bimbingan agama dan bimbingan belajar (bimbel) oleh pengasuh setelah anak asuh pulang dari sekolah formalnya.

Kegiatan PKM dimulai dengan berkunjung ke panti asuhan ini untuk bertemu langsung dengan pengasuh panti. Pada tahap prapelaksanaan, dilakukan wawancara kepada pengasuh untuk mengidentifikasi permasalah yang terjadi di panti asuhan. Permasalahan keuangan muncul akibat adanya ketidakseimbangan antara arus kas masuk dan arus kas yang harus dikeluarkan oleh pihak yayasan untuk mendanai kegiatan operasional panti. Akibatnya beberapa pos pengeluaran harus dieliminasi dari daftar pengeluaran bulanan seperti pengeluaran untuk perbaikan fasilitas panti yang masih bisa ditunda untuk periode selanjutnya pada saat dana yang masuk mengalami surplus.

Beberapa sumber dana yang didapatkan panti diantaranya adalah dari bantuan pemerintah berupa bantuan biaya pendidikan, bantuan dana masyarakat secara sukarela baik melalui donatur atau bantuan dari para dermawan maupun pihak lain yang tidak mengikat, dana bantuan dari zakat, infaq dan shodaqah (ZIS) dari kaum muslimin. Sejauh ini panti memiliki usaha atau bisnis berupa beternak ayam dan budi daya ikan. Namun demikian mereka belum memiliki bisnis di bidang ekonomi kreatif khususnya subsektor fashion dimana saat ini sangat digemari masyarakat. Untuk itu, tim PKM mengusulkan untuk memberikan pelatihan teknik sablon secara manual agar warga panti memiliki modal keterampilan yang sangat berguna sebagai modal hard skill awal melakukan bisnis ini. Disamping itu, keterampilan ini juga bisa menjadi bekal bagi anak asuh kelak saat dewasa untuk menjadi para wirausahawan baru.

Tahap pelaksanaan kegiatan dilakukan mulai pukul 09.00 - 17.00 WIB di ruangan aula panti yang cukup besar. Pada tahap ini, subjek kegiatan, dalam hal ini remaja panti, dikenalkan dengan berbagai macam alat dan bahan yang akan digunakan dalam pembuatan sablon secara manual. Alat dan bahan dari pelatihan ini dapat dilihat pada Gambar 1. Alat penting yang digunakan untuk membuat cetak sablon secara manual salah satunya adalah screen atau saringan sablon. Screen ini berbentuk rangka 
persegi panjang dari kayu dan terpasang kain yang terbuat dari polyster atau nylon. Fungsi dari alat ini adalah untuk mengirimkan tinta pada media penyablonan dengan cara menyaput dengan menggunakan alat bernama rakel. Rakel terbuat dari karet yang dijepit dengan kayu. Fungsi dari rakel adalah untuk menyaput dan meratakan tinta pada screen sehingga tinta tercetak pada media penyablonan. Tulisan atau gambar desain yang ingin dicetak dibuat terlebih dahulu dengan menggunakan software design grafis seperti photoshop atau Corel Draw. Kemudian hasilnya dicetak pada kertas HVS. Bahan penting yang digunakan diantaranya adalah tinta sablon, obat afdruk dan pencuci screen. Tinta sablon digunakan untuk menghasilkan citra visual pada media yang akan disablon sehingga bernilai artistik sedangkan obat afdruk digunakan untuk melapisi screen printing. Melalui proses photokimia, sebagian lubang pori pada screen yang dilapisi akan tertutup oleh emulsi. Setelah selesai digunakan, screen dapat dibersihkan dengan menggunakan pencuci screen.

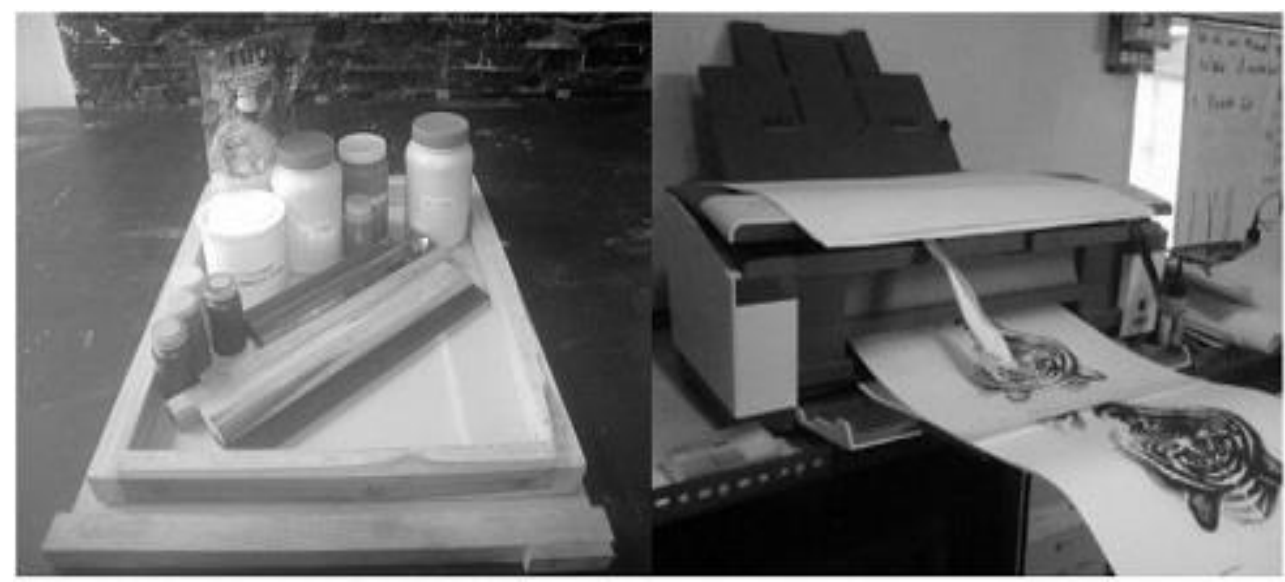

\section{Gambar 1:}

Alat dan Bahan Pelatihan Pembuatan Sablon secara Manual

Selanjutnya disampaikan materi tahapan secara teknis dalam pembuatan sablon dengan memberikan handout materi agar bisa dibaca secara visual dan diikuti dengan sesi tanya jawab. Demo pembuatan sablon dibagi menjadi dua sesi yaitu sesi demo dengan media kertas dan dilanjutkan sesi kedua dengan menggunakan media kaos untuk mencetak sablon yang dapat dilihat pada Gambar 2. 
http://journal.uhamka.ac.id/index.php/syukur

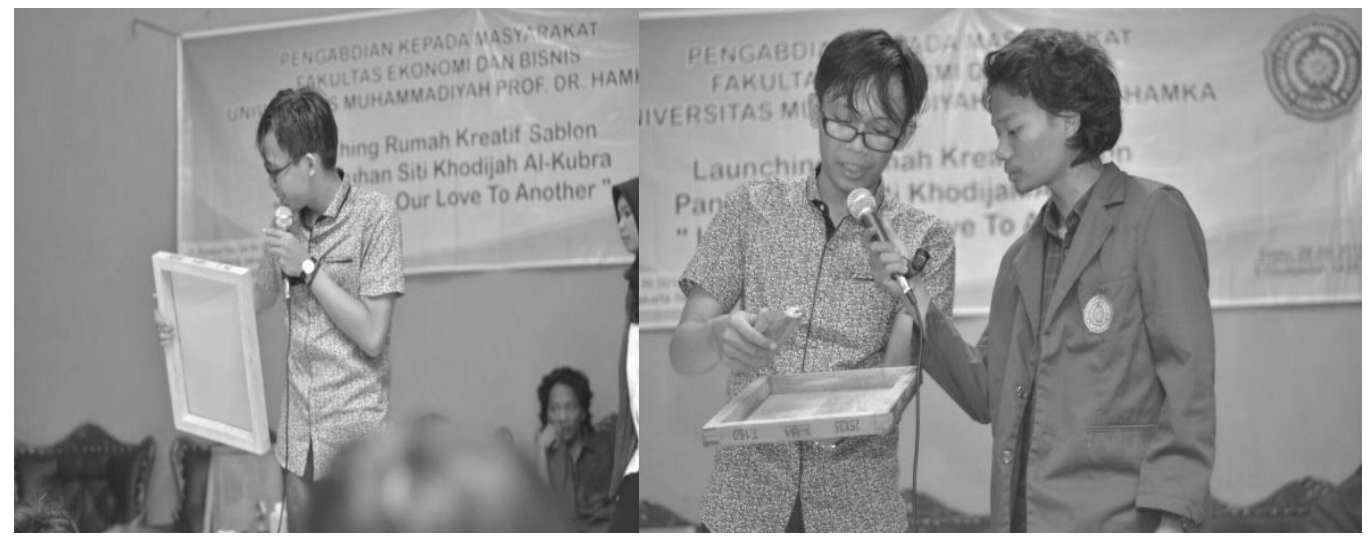

Gambar 2:

Kegiatan Pelatihan Sablon

Remaja panti juga diberikan kesempatan untuk melakukan praktik langsung yang dibimbing oleh tim PKM. Mereka terlihat begitu antusias untuk mencoba dan memiliki ide-ide tulisan dan gambar yang akan disablon ke media kaos (Gambar 3). Produk kaos yang sudah berhasil dibuat dapat dilihat pada Gambar 4.

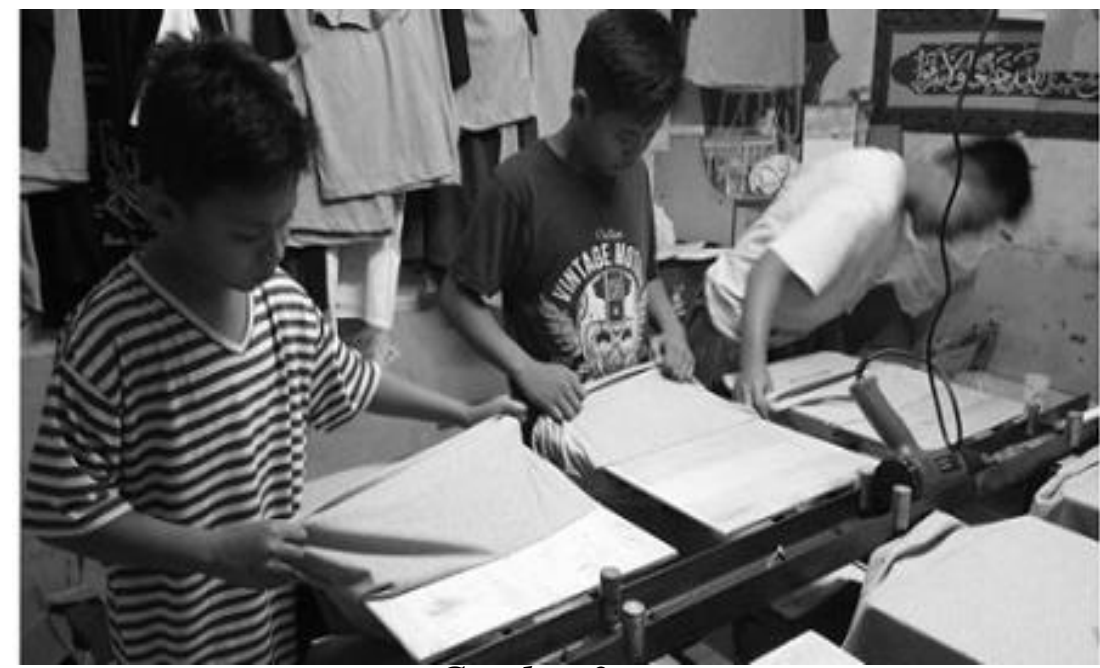

Gambar 3:

Praktik Pembuatan Sablon oleh Remaja Panti

Tahapan pasca pelaksanaan dilakukan dengan melihat hasil produk kaos yang sudah di sablon. Pada Gambar 4 terlihat kemampuan remaja panti dalam menghasilkan produk fashion sudah cukup bagus. Pada tahap akhir ini juga dibagikan tips untuk memasarkan produk jadi dengan melakukan penjualan ke toko-toko pakaian atau menjualnya secara online. Penjualan secara online dapat dilakukan dengan 
memanfaatkan marketplace dengan konsep e-commerce atau dengan membuat online shop sendiri.

Namun demikian, lebih direkomendasikan untuk memanfaatkan marketplace karena memiliki beberapa keunggulan yaitu meminimalkan biaya promosi, persediaan, pemasaran dan proses dalam penjualan online. Kesempatan untuk memperluas area penjualan juga sangat besar. Beberapa marketplace yang dapat dimanfaatkan diantaranya adalah tokopedia dan bukalapak.

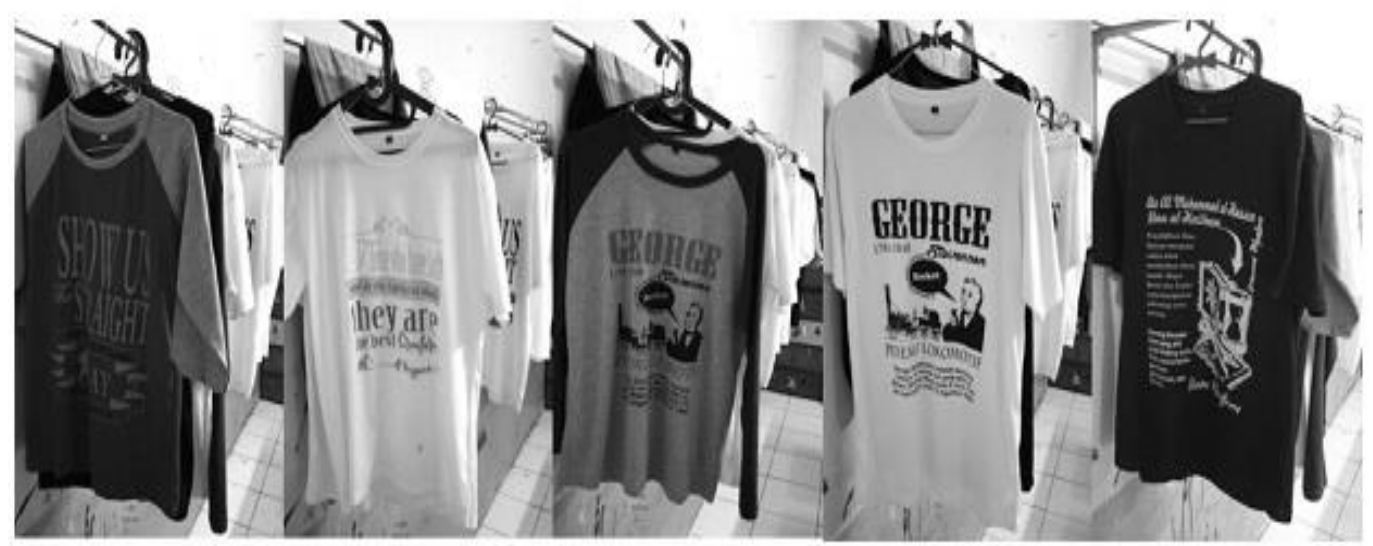

Gambar 4:

Produk Akhir Kaos Sablon

Selain melihat mutu akhir produk dan memberikan tips pemasarannya, dalam tahapan ini juga diberikan pengetahuan untuk mampu melakukan pencatatan laporan keuangan sederhana sehingga dapat menghitung laba dan rugi secara mandiri. Agar program kreativitas dan kemandirian ekonomi ini tetap berlanjut, tim PKM memberikan 2 perangkat sablon manual yaitu perangkat sablon dengan media kertas dan dengan media kaos.

\section{KESIMPULAN}

Kegiatan pengabdian masyarakat berupa pelatihan pembuatan sablon secara manual diselenggarakan oleh fakultas ekonomi dan bisnis UHAMKA. Pada pelatihan ini diuraikan tentang teknik pembuatan sablon secara manual dengan dua media yang berbeda baik dengan menggunakan media kertas maupun dengan media kaos. Kegiatan ini dilakukan dengan tujuan menciptakan sebuah industri ekonomi kreatif kecil. Adapun sasaran dari kegiatan ini adalah untuk meningkatkan kemandirian ekonomi bagi panti 
asuhan Khodijah Al-Kubro. Kemandirian secara ekonomi sangat dibutuhkan pihak panti untuk mengatasi permasalahan sumber dana yang bersifat tidak tetap. Berdasarkan hasil wawancara yang dilakukan dengan pengasuh panti setelah pelatihan sablon, kegiatan ini sangat bermanfaat bagi remaja panti karena meningkatkan wawasan dan kreativitas mereka dan juga sebagai bekal keterampilan mereka di masa depan sebagai calon wirausahawan.

\section{DAFTAR PUSTAKA}

Badan Ekonomi Kreatif Indonesia. 2017. Data Statistik dan Hasil Survei Ekonomi Kreatif. Jakarta: Bekraf Indonesia.

Departemen Sosial Republik Indonesia. 2004. Acuan Umum Pelayanan Sosial Anak di Panti Sosial Asuhan Anak. Jakarta: Departemen Sosial RI

Howkins, John. 2001. The Creative Economy: How People make money from ideas. The Penguin Press.

Peraturan Gubernur Provinsi Daerah Khusus Ibukota Jakarta. 2015. Bantuan Biaya Personal Pendidikan bagi Peserta Didik dari Keluarga Tidak Mampu melalui Kartu Jakarta Pintar. Jakarta.

O'Cass. 2000. An Assessment of Consumers' Product, Purchase Decision, Advertising and Consumption Involvement in Fashion Clothing. Journal of Economic Psychology, Vol. 21, pp. 545 - 576.

O'Cass. 2004. Fashion Clothing Consumption: Antecedents and Consequences of Fashion Clothing Involment. European Journal of Marketing, Vol. 38 (7), pp. $869-882$.

Simatupang, T. M. 2008. Perkembangan Industri Kreatif. School of Business and Management of the Bandung Institute of Technology. 